\title{
Una revista de Herrera y Reissig
}

$\dot{1}$

N Uestra tarea es bien modesta: publicar unos cuantos datos sobre una revista literaria apenas conocida del célebre poeta uruguayo Julio Herrera y Reissig. Nos referimos a La Nueva Atlántida de la que sólo alcanzó a publicar dos números, correspondientes a los meses de mayo y junio del año 1907. ${ }^{1}$

Una mirada retrospectiva a las postrimerías del siglo pasado en el Uruguay, revela la coexistencia de una gran variedad de corrientes intelectuales. Como en casi todos los países hispanoamericanos, el romanticismo persistía aún. Tabaré es del año 1886, y las firmas de los últimos románticos (Zorrilla de San Martín, Acevedo Díaz) aparecen en los periódicos y revistas del día, al lado de las de autores mucho más jóvenes. A ese romanticismo tardío se oponían el positivismo de Spencer y el realismo y naturalismo europeos. $\mathrm{Y}$ al margen de lo tradicional poco a poco se va incubando el esteticismo finesecular. De esa multiplicidad de ideologías, pues, arranca la literatura moderna urtguaya, que ostenta nombres de tan alta categoría como los de Rodó, Herrera y Reissig, Florencio Sánchez, Quiroga; los Vaz Ferreira, Agustini, Reyles, Viana y otros muchos. Si los Anales del Ateneo (1881-1886) reflejan con fidelidad los ideales de la segunda generación romántica, la Revista Nacional (1895-1897); redàctada por Rodó, Pérez Petit y los hermanos Mártínez Vigil, da un paso definitivo hacia nuevas modalidades estéticas. Además de los estudios de Pérez Petit dedicados a los más recientes maestros europeos, sus páginas recogen las firmas de Darío, Lugones, Santos Chocano, Gómez Carrillo, Jaimes Freyre, Salvador Rueda, Díaz Rodríguez ... En todas partes se abren paso las novedades artísticas? 
en Buenos Aires Rubén Darío publica Los Raros (1896) y Prosas profanas (1896); Gómez Carrillo manda sus crónicas elegantes de París; Rodó en 1899 da a la estampa su famoso estudio sobre Darío; etcétera.

Lo que más nos interesa señalar aquí, sin embargo, es que en 1899 Herrera y Reissig, todavía poeta con dejos románticos aunque datan del mismo año "Holocausto" y "Wagnerianas", lanza al mundo literario de Montevideo La Revista, periódico literario y científico quincenal que se publicó desde agosto, 1899, hasta julio del año siguiente. ${ }^{2}$ Veintidós números y un total de unas quinientas sesenta páginas, encabezadas por su beligerante "Programando". No sólo abunda la producción literaria en ese período, sino también florecen las revistas: la Revista del Salto (1899-1900) de Horacio Quiroga, Vida Moderna (1900-1903) y otras muchas; la más fugaz de todas, La Nueva Atlántida (1907) de Herrera y Reissig.

Llegamos al año 1907. Con la publicación de La Nueva Atlántida, Herrera y Reissig reanuda sus esfuerzos editoriales que habían sido interrumpidos por la desaparición de La Revista hacía unos siete años. El poeta disfrutaba de cierta celebridad literaria en Montevideo. Es la época de la Torre de los Panoramas (1902), del famoso Decreto (1904), de la polémica con Roberto de las Carreras (1906). Se ha definido ya como audaz reformador en la poesía lírica; ha escrito una buena porción de su obra definitiva, y los periódicos del día publican sus colaboraciones en verso y en prosa.

Los dos' números de su revista "de altos estudios" (mayo-junio de 1907) representan un total de ciento cincuenta y dos páginas de texto. ${ }^{3}$ Se publicó en la Tipografía de la Escuela Nacional de Artes y Oficios, y la dirección estuvo en la famosa Torre de los Panoramas, calle Ituzaingó, número $235 .{ }^{4}$ Es muy probable que $L a$ Nueva Atlántida haya tenido tan corta vida por la muerte del padre de Herrera y Reissig, acaecida en julio de 1907. Años atrás había contribuído generosamente a sostener la primera revista dirigida por el poeta. Es lógico suponer, pues, que Herrera y Reissig haya abandonado su proyecto, no sólo por la falta de ayuda material necesaria en tales empresas, sino también por haberse agravado de su padecimiento cardíaco. Se recordará que permaneció retirado de la redacción de La Revista, por algún tiempo, a causa de su salud. En efecto, tras el inesperado fallecimiento de don Manuel Herrera, sobrevinie- 
ron apuros económicos para toda la familia. A juzgar por ciertas notas optimistas, que anuncian futuras colaboraciones de literatos distinguidos, ${ }^{5}$ de ninguna manera se esperaba la suspensión del periódico. Por lo demás, un estudio de Scipio Sighele ("La obra de G. D'Annunzio ante la psiquiatría", II, 115-121) y otro de Raúl de Alceda ("La voluntad exteriorizada", Ir, 105-113) no llegaron a concluirse.

Poco hemos podido averiguar con respecto a la génesis de $L a$ Nueva Atlántida. Sin duda el proyecto iba madurándose en el pensamiento del poeta porque ya en enero de 1907 había escrito a Armando Vasseur:

Querido Vasseur: Ruégole con cien lenguas que cincele para la gran revista La Nueva Atlántida un gran bombo que estremezca a todo el país y haga abrir una boca de cocodrilos en éxtasis a los excelentes burgueses para que anuncien sus casas, etc., etc.

Por informes le adjunto la circular de comercio; será una revista 1,001, exquisita, cruel, abismática, aterradora, oceánica, hierofántica, inadjetivable.

Espero que El Día del lunes o martes se engalane con el anuncio a gran orquesta de mi gran revista.

Tendríamos que hablar mucho y convenir la forma en que su colaboración nos vendrá desde Europa. Usted podrá hacernos mucho bien y enviarnos otros colaboradores desde aquellos mundos. En fin, venga y hablaremos.

No deje de hacer el suelto para la revista. ${ }^{6}$

Aunque sí cumplió con lo pedido, de hecho Vasseur no colaboró en los dos números de la revista. También se reproduce en el periódico una crónica de La Razón, firmada por "Aladino" (I, 74-76), que auncia, entre calurosos elogios de Herrera y Reissig y su valor como poeta, la publicación de La Nueva Atlántida para abril inmediato.

En la prosa inicial de su publicación, "En el circo" (1-3), Herrera y Reissig expone el amplio programa de La Nueva Atlántida. En primer lugar afirma la necesidad espiritual de fundar su revista:

La aparición de una gran revista en nuestra América contemporánea es una estrategia y es un símbolo. Todo la reclama. Es un maná de redención y de nueva vida para los pueblos. Es que el momento es oportuno, digámoslo alto. Casi religioso. (1) 
Y tras la evocación de la utopía de Platón, Herrera y Reissig se proyecta a un futuro soñado:

El meridiano filosofal de la historia pasa por la hora presente en que nuestro estandarte evoca la más risueña utopía de Platón: iAtlántida feliz! ... plasmada en bella realidad más tarde ... y que la eterna evolución de las ideas renovará en cien moldes prestigiosos, como un artista sumo haciéndola surgir distinta, preclara, idealizada, otra Atlántida, aún más feliz, tan desemejante de la contemporánea, como la Anérica de Colón difiere de la hipótesis del maestro etéreo. (1-2.)

La revista no será exclusivamente literaria. Aspira a recoger todo el pensamiento moderno:

A esa finalidad super-consciente de los nuevos rumbos sociales, a ese fenomenismo sublime de las causas complejas y de los profundos albores del alma que primaverizan nuevas floras del Pensamiento y del Arte - tiende su prora de luz el Argos de nuestra briosa aventura-, mientras nuestros ojos se hunden meditabundos en el abismo eternal. (2:)

Y luego se refiere el poeta a la literatura del día y la del futuro:

Somos incipientes. Somos obscuros. Lo que relumbra es superficial: brillo de mica y de pantano. Todo está por hacerse. E1 camino es torvo. La lontananza sombría. Se pretende forjar Hércules para el futuro. Y Apolo duerme. Y Euterpe y Polymnia están mudas. $\mathrm{Y}$ el templo de Minerva cerrado yace.

Una multitud de acróbatas profanos trepa por sus columnas, entre los peristilos y las paredes ruinosas. (2.)

Ya no parece ser el mismo que años atrás había trazado las auda-cias de "Programando", y ahora se patentiza un plan americanista de acción, ideado por el poeta en los párrafos que a continuación transcribo:

Cincelemos el nuevo tipo social: el varón fuerte y digno: la Conciencia; el microcosmos armónico; el as futuro de la especie. Alta prédica. Cursos escolásticos para el pueblo. Escuelas de agronomía, agropecuaria y de mineralogía en los departamentos. Enseñanza nocturna para obreros. Difusión de las Artes plásticas. Universidad libre: Ateneo de verdad. Liceos de enseñanza preparatoria y gimnasios en toda la República. Educación política de las Masas. Fiestas escolares. Democratización de las Ciencias. 
Alta pedagogía. Centro de Bellas Artes. Glorificación histórica de los héroes y de los grandes hombres. Exposiciones y Certámenes cosmopolitas. Fundación de una Academia de honor:

Tracemos Ia periferia psicológica futura de la nacionalidad. Concursos. Academias. Baños públicos. Liceos populares. Congresos internacionales de estética. Certámenes de artes plásticas. Propiedad literaria legalizada por el Estado. Asociaciones de escritores amigos. Retribución del trabajo cerebral. Franquicias y protección a la publicidad. Subvenciones a los intelectuales y ubicación de los literatos en los puestos públicos de alta categoría y en la diplomacia, para mayor gloria de la nacionalidad. Pensiones de estudio en el extranjero. Juegos florales. Premios. Lauros. Becas. Cátedra de enseñanza libre para el pueblo. Apoteosis del talento. Estatuas de los más altos espíritus en plazas y paseos públicos. (2-3.)

Así era su sueño de una nación progresista. Tal programa social para el futuro del país, no deja de recordarnos en ciertos aspectos la actuación de José Vasconcelos en el Ministerio de Educación Pública, en México, hacia 1921. Además del afán nacionalista, la revista ambicionaba resonancias más universales: una dignificación de lo americano en el arte y en la política. La Nueva Atlántida, pues, anhela ser revista de las Ciencias y del Arte, no portavoz de una sola escuela poética, y a toda manifestación del pensamiento moderno abrirá sus columnas. ${ }^{7}$

Se pone de manifiesto esta actitud tolerante en la sección permanente titulada "El problema del alma en la sociedad moderna". La nota de redacción que la inaugura $(\mathrm{I}, 18-20)$ se debe a Francisco C. Aratta, el más asiduo colaborador de la nueva revista. Este no sólo se refiere a los avances de las ciencias psíquicas, sino también insiste en la imparcialidad de La Nueva Atlántida, "tribuna abierta a todos los ideales" que "se inclina a escuchar a todos los que sepan hablar con altura de estilo y nobleza de pensamiento." ( $\mathbf{r}, 19) .{ }^{8}$ Tras breve alusión a la acogida fervorosa dispensada por la prensa y el público a la revista, el mismo Aratta, autor de la prosa inicial del segundo número ("Las nuevas nebulosas del pensamiento"), exagera los elevados ideales que motivan la publicación:

¿Bólido o astro? No lo sabemos, todavía; pero es luz que viene de lo alto, de lo superior de la conciencia, de lo más fuerte de la voluntad, de lo más luminoso del Pensamiento... (II, 77.) 
LA NUEVA ATLANTIDA ... abre un arco triunfal para que pasen todos los artistas, los pensadores, los que han hecho un culto de la Ciencia y un estímulo generoso del Arte... (II, 78.)

Y más adelante, afirmando que La Nueva Atlántida se enorgullece de ser la primera revista en América que ha abordado científicamente el magno problema del alma en la sociedad moderna, su prosa, con frectencia hiperbólica, se torna oratoria altisonante. Basta un ejemplo:

¡En ruta, pues, luchadores de la voluntad, audaces creadores del ideal latino! No llega a la cumbre el que se queda atrás, entonando canciones plañideras, sino el que escala riscos, orilla abismos, y clava el bastón ferrado en las cimas, donde halla una nieve tan pura que apenas rozóla con sus alas el águila real de las montañas.

¡En ruta! ¡ en ruta! LA NUEva ATLANTIDA os va abriendo camino; como el tenebroso albatros de Hugo, penetra en las regiones desconocidas del porvenir, aspirando el alma del mundo, a plena inmensidad de las ideas, en el vértigo de la ascensión, chamuscando sus alas de sombra en las estrellas de las nuevas conquistas y de las nuevas nebulosas del pensamiento. (II, 80.)

Desde luego, La Nueva Atlántida, por su pronta desaparición, no pudo llegar nunca a realizar tan altos principios. Al respecto, nos permitimos citar en parte, sin embargo, un artículo encomioso firmado por Julio Romano que se reproduce al final del último número de la revista (II, 148-152). El autor se refiere a la escasez de revistas y libros en el Uruguay, que se halla "bajo el imperio de una apatía desconsoladora" (148) y, aludiendo a La Nueva Atlántida, dice:

... la super-revista de Julio Herrera y Reissig, que irradió como un Biela anormal de larga cauda pontificia, en el horizonte, desolado. Falta estímulo y hay exceso de virus en el ambiente, mucha mediocridad triunfante, mucho oropel bárbaro hecho como el manto de arleouín con la tela de otros mantos... (150.)

II

Con respecto a las colaboraciones en la revista predomina la poesía sobre los otros géneros literarios. No todos los versos alli publicados son modernistas; los hay también que manifiestan clara- 
mente su herencia romántica. A las composiciones inéditas, de calidad sumamente desigual, sin embargo, se suma la reproducción de cinco poemas de Amado Nervo (I, 64-68) ${ }^{9}$ y otro de Rubén Darío (II, 114). ${ }^{10}$ En efecto, un recorrido rápido de los colaboradores revela firmas de poetas que han alcanzado cierta fama y otras muchas hoy olvidadas por los historiadores de las letras ríoplatenses.

El poeta y dramaturgo argentino José de Maturana colabora con cinco sonetos alejandrinos de corte modernista, agrupados bajo el título de "Tardes fantásticas" y fechados en Buenos Aires, 1907 (I, 14-17). Más que nada, recuerdan el género llevado a suma perfección por Herrera y Reissig mismo en Los éxtasis de la montaña y también por Leopoldo Lugones. Tal semejanza se ve con claridad en ciertas imágenes ("La tarde está cargada de sol, como un problema / que en álgebras de ensueño resuelve el infinito") y más extensamente en la estrofa que copiamos:

Bajo una gran capota de muselina extraña se aleja de un imperio la tarde moribunda, que de un fulgor violeta los ámbitos inunda como si diese un grande bostezo en la campaña.

Contertulio de La Torre, Carlos López Rocha, cuyo libro Palideces y púrpuras, (Buenos Aires, 1907) mereció un prólogo de Herrera y Reissig, contribuye con un soneto endecasílabo ("La Fuente", I, 41) que revela también las ineludibles huellas de la entonces imperante escuela. Sus versos se caracterizan por una decoración suntuosa muy en boga y se pueblan de imágenes típicas del modernismo más exterior ("cuello diamante de cisne o serpiente", "y es beso de iris y aljófar de espuma").

A1 poeta y político Emilio Frugoni, que alcanza renombre después $y$, en esta época, ya era autor de dos libros en verso, se debe un canto de angustia y de presentimiento ("Paisaje de invierno", I, 33-34) que forma parte de El eterno cantar, (Montevideo, 1907). Novedosa por su libertad técnica, esta poesía recoge ciertos ecos modernistas en un fondo netamente romántico. Con reminiscencias de Bécquer y otros románticos de tono menor, Benjamín Fernández Medina, mejor conocido como cuentista, se mantiene fiel a la tradición poética, en su silva "Alto silenzio regna...", (I, 50-51). También de filiación romántica es "Delectación amorosa" de Illa Mo- 
reno, autor de Rubies y amatistas, (Montevideo, 1907). Ese poema está éscrito en cuartetos octonarios (8 más 8), con rimas agudas en los versos pares. Otra poesía completa el primer número de la revista : una delicada composición sin título $(r, 69)$ de María Eugenia Vaz Ferreira, antigua colaboradora de La Revista, que no incorpora el poema, cuyo primer verso reza así: "Ay de las melodiosas serenatas!", a su obra definitiva La isla de los cánticos, (Montevideo, 1924).

Sin tener en cuenta la poesía de Rubén Dario ya apuntada, el segundo número de La Nueva Atlántida sólo publica originales de Pedro P. Náón ("Là musa de Guido", II, 81-82), de Juan Más y Pi ("La canción nueva", Ir, 93-95) y de Angel Falco ("Las musas galantes", II, 142-143). En calidad son, por lo demás, inferiores a las composiciones recogidas en el número anterior. El poema de Naón, asiduo colaborador en La Revista, se caracteriza por un derroche de alusiones mitológicas, todas referentes al arte del poeta en su taller helénico; el de Más y Pi, contertulio de La Torre, es un himno altisonante a la vida, cuya última estrofa en endecasílabos representa a nuestro ver lo peor de una retórica todavía romántica:

$$
\begin{aligned}
& \text { Y en esta eterna marcha hacia adelante, } \\
& \text { de acero y bronce sea nuestra lira; } \\
& \text { hirientes para el mal sean sus ritmos, } \\
& \text { y sonoras como ellos nuestras rimas. } \\
& \text { De acero y bronce sean et la lucha } \\
& \text { para el combate entre enemigas filas... } \\
& \text { De acero y bronce sean en el triunfo } \\
& \text { cual sonoras campanas bien tañidas... } \\
& \text { De acero y bronce cual las almas libres } \\
& \text { en su ascensión a la Suprema Vida... }
\end{aligned}
$$

Y por último, los tres sonetos alejandrinos de Angel Falco ("Friné", "Cleopatra", "La Maintenón") manifiestan, como se desprende de los títulos mismos, una predilección por el culto de lo exótico, tan gustado por muchos poetas de aquel entonces.

En resumidas cuentas, pues, la poesía de La Nueva Atlántida es representativa de las corrientes estéticas del dia: un romanticismo que perdura y un modernismo suntuoso, de tema helénico y exótico, que puede relacionarse con el parnasianismo. Según ya dijimos, el valor lírico de esos poemas es muy desigual; pero deben 
destacarse las colaboraciones de Maturana, de Frugoni, de María Eugenia Vaz Ferreira como las mejores de la revista.

En cuanto a la prosa literaria de La Nueva Atlántida, el primer número se enriquece con un ensayo crítico de José Ingegnieros, "La exégesis de Dante" ( $\mathrm{I}, 4-13$ ), fechado en Florencia, 1906. El escritor argentino, en varias ocasiones colaborador de La Revista, comenta las recientes obras de Sardou, Bovio y D'Annunzio que pretenden recrear a Dante. La máxima figura de las letras italianas, según Ingegnieros, no puede abstraerse del propio mundo creado por su genio en La Divina Comedia ni tampoco concebirse en la vida moderna de hoy. Para buscar a Dante, hay que ir a la obra misma, puesto que el poeta pertenece plenamente a otra vida y a otros tiempos. Una colaboración ("El ideal de las letras castellanas", I, 42-49) de Francisco Aratta, exalta los valores vitales de la literatura, frente a las puras bellezas formales cultivadas por autores que han renunciado a la vida. También el mismo Aratta contribuye al segundo número con otro trabajo en prosa, de escaso interés literario ("Un centauro de la raza", II, 122-127). Ya serenadas las relaciones entre Herrera y Reissig y Víctor Pérez Petit, la revista recoge de éste un cuento gracioso e irónico, "Examen de latinidad" ( $\mathrm{r}, 52-63$ ), que evoca aspectos humorísticos de la vida de estudiante. Si bien se publican los originales de Scipio Sighele ("La obra de D'Annunzio ante la psiquiatría", II, 115-121) y del amigo de Horacio Quiroga, Atilio C. Brignole ("La armonía en el contraste", II, 144-147), merece breve noticia una crónica literaria de Andrés L. Demarchi ("La muralla", II, 128-141). Ese artículo, motivado por el obsequio de la última obra dramática de Coelho Netto La muralla, además de realzar la producción y el talento literarios del dramaturgo brasileño, subraya la importancia del intercambio intelectual entre países hispanoamericanos y recuerda, al respecto, los esfuerzos, fracasados a última hora, de unos jóvenes para llevar sus obras al Brasil. ${ }^{11}$

Por su ausencia una firma nos llama la atención: la del director de La Nueva Atlántida. Aunque Julio Herrera y Reissig publicó seis poesías, cuatro prosas y algunas notas de redacción en $L a R e-$ vista ${ }^{12}$ años atrás, sólo es del poeta la prosa inicial del periódico ("En el circo") que firma "La Dirección". Una nota (Ir, 141) anun- 
cia para el próximo número, que no llegó a publicarse, la inclusión de un artículo de estética del poeta: "El círculo de la muerte". ${ }^{13}$

Ante todo, La Nueva Atlántida fué una promesa, un esfuerzo heroico del poeta Herrera y Reissig en pro de la cultura. Otra insigne prueba de su generosidad. Conviene recordar el plan americanista de su periódico, tan significativo en vista del consabido exotismo del poeta. Debido a la vida fugaz y la calidad del conjunto, los propósitos que motivaron la fundación de La Nueva Atlántida, por desgracia no pudieron llegar a cumplirse cabalmente. Los apuntados colaboradores futuros no habrían dejado de aumentar infinitamente su prestigio literario e histórico. Tal como es, no obstante, reafirma el florecimiento intelectual en Montevideo durante el primer decenio del siglo actual. ${ }^{14}$

\author{
Allen W. Phillips, \\ Universidad de Michigan.
}

\title{
$\mathrm{N} O \mathrm{TAS}$
}

1 Con respecto a La Nueva Atlántida, la bibliografía crítica es sumamente escasa. En su pequeña crónica "De La Revista a La Nueva Atlántida" [Número, Ir, (núms. 6-7-8, enero-junio, 1950), pp. 293-299] el fino crítico uruguayo José Pereira Rodríguez dice textualmente: “... No he podido obtener ningún dato relacionado con esta 'revista de altos estudios', pues en ninguna de las bibliografías del poeta, publicadas hasta la fecha, la he visto mencionada... César Miranda, el albacea literario de Herrera y Reissig y su amigo más íntimo, vagamente recuerda ahora que Julio publicó una revista ... después de $L a$ Revista... La hermana de Herrera y Reissig, al dedicar algunas páginas de su biografía del poeta a La Revista no menciona en ningún momento a La Nueva Altántida...", (p. 295).

Por lo demás, Roberto Bula Piriz en su largo estudio reciente sobre la vida y obra del poeta [Revista Hispánica Moderna, xvIr, (núms. 1-4, enerodiciembre, 1951), pp. 11-93] apenas dedica media página (p. 41) a la revista en cuestión, aunque sí cita una carta dirigida por el poeta a Armando Vasseur, a la que nos referimos más adelante.

2 Esta publicación del poeta es documento imprescindible para el estudio de la iniciación del modernismo en el Uruguay y ha merecido amplio comentario por la crítica. [Sobre ese tema puede consultarse el excelente estudio de Raúl Montero Bustamante, "La Revista de Julio Herrera y Reissig", Revista Nacional, viIr, (núm. 92, agosto de 1945), pp. 304-310, que se ocupa del primer número del periódico.] Aunque su mismo director era todavía un 
joven prácticamente desconocido en aquel entonces, una lista parcial de sus colaboradores confirma el prestigio de La Revista: María Eugenia Vaz Ferreira, Zorrilla de San Martín, Carlos Martínez Vigil, Elías Regules, Benjamín Fernández y Medina, Roberto de las Carreras, Carlos Reyles, Javier Viana, José Ingegnieros, José Santos Chocano, etcétera. De hecho, en sus páginas aparecen firmas de casi todos los países de América.

3 Al primer número corresponden las páginas 1-76 de texto, más otras cuatro de avisos $(77-80)$; al segundo, las páginas $77-152$, con cuatro de avisos numeradas I-rv.

4 Copio ese dato del estudio ya citado de Pereira Rodrígtuez (p. 295), porque el tomo que tengo a mano no registra ese detalle.

5 Entre ellos se destacan, por ejemplo, los siguientes: Paul Groussac, Andrés L. Demarchi, Florencio Sánchez, José Ingegnieros, María Eugenia Vaz Ferreira, Daniel Martínez Vigil, José Santos (II, 92). Otra nota (II, 104) apunta los siguientes nombres: José E. Rodó, Juan Zorrilla de San Martín, Benjamín Fernández y Medina, Carlos Martínez Vigil. Con todo, una nómina de alta categoría, y se notará que varios son antiguos colaboradores de $L a$ Revista.

En la lista anterior el nombre de José E. Rodó, quien nunca colaboró en La Revista, llama la atención en virtud del antagonismo literario y político que separaba a los dos escritores. Sobre todo a partir de 1900 son menos cordiales, en efcto, sus relaciones personales. Al llamado "decadentismo" literario de Herrera y Reissig se oponen los ideales americanistas de Rodó. [Ver sobre ese tema el interesante y bien documentado estudio de E. Rodríguez Monegal, "Rodó y algunos coetáneos", Número, Ix, (núms. 6-7-8, enero-junio, 1950), pp. 300-313.]

6 Alvaro Armando Vasseur, Maestros cantores, (Madrid: Talleres de don Juan Pueyo, 1936), p. 212.

7 La crónica de "Aladino", antes aludida, también insiste en los ideales americanistas de la nueva revista: "Dada la existencia, ... de una gran patria americana con resumen y por cima de todas las patrias pequeñas, urge necesariamente la publicación de una revista que vivifique ya que parece agotarse por dispersa, en un haz maravilloso, la producción americana, de triunfadoras florescencias de juventud, estrechando a la par, para hacerlas más fuertes y más íntimas, las relaciones culturales de América..., $(\mathrm{I}, 75)$.

8 No es nuestro propósito estudiar las colaboraciones que carecen de interés literario. Aunque sea de paso, las apuntamos: (número I) César Lombroso, "Sobre fenómenos espiríticos y su interpretación", 21-32; J. M. Palmarini, "La ciencia y el espiritismo, (entrevista con Enrique Morselli sobre las investigaciones medianímicas)", 35-40; (número II) Manuel Herrera y Reissig, "Henry George. Su escuela de economía política. E1 sistema económico del single tax. Prólogo a un estudio económico", 83-92; F. Zingarópoli, "Lom- 
broso y el padre Franco frente a los fenómenos medianímicos", 96-104; Raúl de Alceda, "La voluntad exteriorizada", 105-113.

Dada la aparente importancia concedida a los estudios del espiritismo cabe señalar que Herrera y Reissig mismo se interesó brevemente en él hacia 1906. [Ver: Bula Píriz, Ob. cit., p. 41].

9 A Jardines interiores (1905) pertenecen "Vieja llave", "Tan rubia es la niña que..." y "Esta niña dulce y grave"; a Poemas (1901) "La[s] cigüeña[s]"; y a Misticas (1904) "A Kempis".

10 El poema de Darío es el Ix de Cantos de vida y esperanza (1905).

11 Unas notas bibliográficas, noticias de periódicos, etcétera, terminan cada número: r, pp. 72-76 (e incluye el artículo elogioso de "Aladino") y Ir, pp. 148-152 (aquí se recoge el trabajo de Julio Romano sobre la aparición de La Nueva Atlántida, pp. 148-150).

12 Los trabajos de Herrera y Reissig publicados en La Revista son los siguientes: (Poemas) "La musa de la playa", "Holocausto", "Wagnerianas", "A Guido y Spano", "Psicología de unos ojos negros", "Plenilunio" y (Prosas) "Progtamando", "Conceptos de crítica", "Sueño de oriente" (reseña crítica) y "La Chacra" (reseña crítica).

13 Ese artículo, publicado aparentemente por primera vez en El Diario Español de Buenos Aires, el 8 de marzo de 1905. [Ver: Bula Píriz, Ob. cit., p. 84], fué recogido después de la muerte del poeta por Juan Más y Pi: Páginas escogidas, (Barcelona: Maucci, 1914).

14 Terminadas estas páginas, nos llegó el excelente trabajo de José Pereira Rodríguez titulado "Las revistas literarias de Julio Herrera y Reissig", que se publicó en los siguientes números de la Revista Nacional de Montevideo: año XIT, (núm. 132, dic. de 1949), pp. 345-352; año XITI, (núm. 143, nov. de 1950), pp. 178-189; y año xv, (núm. 161, mayo de 1952), pp. 205-216. En las dos primeras partes de su artículo, Pereira Rodríguez estudia respectivamente los dos tomos que alcanzó a publicar La Revista y en la última se dedica a La Nueva Atlántida.

El estudio de Pereira Rodríguez, que lleva el sugestivo subtítulo de " $L a$ Nueva Atlántida, ¿desconocida u olvidada?", es bien distinto en forma y en contenido del nuestro, aunque nos es grato ver que coincidimos en más de un punto de vista.

Sin embargo, queremos llamar la atención hacia unos cuantos datos, para nosotros desconocidos, que el crítico uruguayo ha incorporado a su trabajo. Por ejemplo, el "Julio Romano" ("brioso paladín del verso nuevo", II, 148) que celebra la aparición de La Nueva Atlántida en el artículo que citamos, no es otro que el amigo entrañable del poeta, César Miranda. Asimismo la firma "Raúl de Alceda" es un pseudónimó empleado por el más entusiasta colaborador de la revista, Francisco C. Aratta. Por lo demás, Pereira Rodríguez acierta a dar datos precisos sobre el porvenir de unas cuantas colaboraciones apareci- 
das en las páginas de La Nueva Atlántida. Si se nos permite decirlo, lo que parece faltar en su estudio es un juicio sintético sobre la calidad de las colaboraciones literarias allí publicadas. No obstante, hemos querido transcribir en parte el párrafo final de su ensayo: "... En La Revista, junto a los escritores nuevos y viejos, congregó a un núcleo de militares jóvenes para que tuviesen tribuna propicia para sus inquietudes técnicas. En la fugaz vida de La Nueva Atlántida se puso de manifiesto una preocupación que atañe más que al 'sentimiento trágico de la vida', a la preocupación metafísica por el destino del alma. $Y$ en ambas manifestaciones, Herrera y Reissig se condujo con una ejemplar generosidad, no muy frecuente en el ámbito literario, para estimular a los nuevos, para respetar a los viejos y para darles a todos los obreros intelectuales, amplio campo de acción... Individualista como era en la elegante y refinada prestancia de su poesía, supo hacerse a un lado para dejar que el reducido espacio de sus revistas acogiera la labor literaria de los demás...". (p. 216). 
